\title{
Relationship of cigarette smoking and social class to birth weight and perinatal mortality among all births in Britain, 5-11 April 1970
}

\author{
D RUSH AND P CASSANO
}

From the Division of Paediatric and Perinatal Epidemiology, Albert Einstein College of Medicine, Bronx, New York, USA

SUMMARY The joint associations of maternal cigarette smoking and social class on perinatal outcome were studied in the 1970 British birth cohort (British Births). Whereas smoking was much more frequent among women in social classes III, IV, and V, there was little difference in the birthweight decrement associated with smoking across class. Perinatal mortality, however, was increased only among smokers in the manual social classes. Thus whereas the offspring of more privileged smokers were not protected from intrauterine growth retardation, they did not suffer from increased perinatal mortality. Observations of other populations suggest a possible nutritional mediation of this protective effect.

Maternal cigarette smoking has been found to be consistently and strongly associated with decreased birth weight, since the association was first reported by Simpson, ${ }^{1}$ but although the relation of cigarette smoking to perinatal mortality is of considerable magnitude, and present in most populations studied, ${ }^{2}$ it is not universal (D Rush et al, unpublished data). The most important factors which appear to modify the relation between maternal smoking and perinatal outcome are maternal weight gain, ${ }^{34}$ diet $^{56}$ and social status ${ }^{2}$ (D Rush et al, unpublished data). The data of the 1970 British births cohort ${ }^{78}$ allowed us to re-explore the interrelation of smoking, social class, birth weight, and perinatal mortality in the total population of births in Britain born 5-11 April 1970.

This re-exploration was particularly appealing since so much of our understanding of these issues was gained from the study of all births in Britain in one week in March 1958. ${ }^{9}{ }^{10}$ On reanalysis of the data of the 1958 study we found that in social classes I and II the excess perinatal mortality associated with cigarette smoking was $12.9 \%$, whereas it was over $40 \%$ among those of lower social class. ${ }^{2}$ Thus we were eager to see if this pattern was reflected in the outcome among children born 12 years later.

\section{Methods}

The mothers of almost all children born in Britain from 5 to 11 April 1970 were interviewed by midwives in the immediate postpartum period, and in addition to information on marital status and on the current and past pregnancies women were asked if they ever smoked, how much, and, if they were no longer smoking when they had stopped. Thus current smoking refers to the few days immediately postpartum.

Social class was coded according to the Registrar General's 1970 classification. Details of the survey have been reported previously. ${ }^{78}$ We here report on analyses on all singleton births for whom there were valid data on birth weight, perinatal mortality, social class, and smoking $(n=16688)$. Multiple regression analyses were performed using the statistical package for the social sciences (SPSS).

\section{Results}

SMOKING AND SOCIAL CLASS (table 1)

Of all women delivering singletons in this survey, $41.3 \%$ reported smoking at term. Rates differed remarkably by social class, particularly for those smoking more than four cigarettes a day among whom effects on the fetus were greatest. In social class I, $15.4 \%$ of women were smoking five or more cigarettes a day at term, as were $46.0 \%$ in social class V. Conversely, $71 \cdot 6 \%$ of women in social class I were not smoking at conception, with a regular gradient from social class I to social class $V$; only $43 \%$ of women of social class $\mathrm{V}$ began pregnancy not 
Table 1 Cigarette smoking at term, mothers of singletons born 5-11 April 1970 in Britain

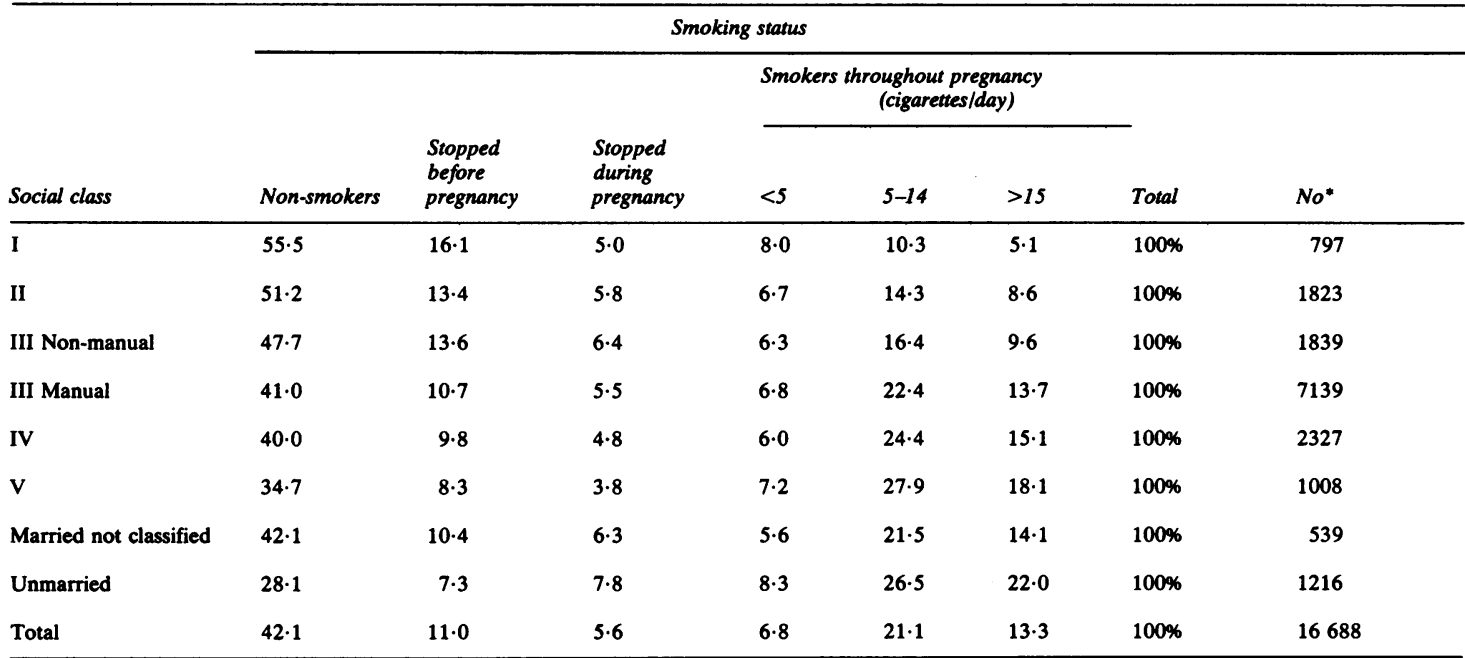

"For 498 women, it was uncertain whether they stopped smoking just before or just after conception.

Table 2 Mean birth weight $(g)$ by amount smoked at term and social class, singletons, born 5-11 April 1970 in Britain

\begin{tabular}{|c|c|c|c|c|c|c|c|}
\hline \multirow[b]{3}{*}{ Social class } & \multicolumn{6}{|c|}{ Smoking status } & \multirow[b]{3}{*}{ All singletons } \\
\hline & \multirow[b]{2}{*}{ Non-smokers } & \multirow{2}{*}{$\begin{array}{l}\text { Stopped } \\
\text { before } \\
\text { pregnancy }\end{array}$} & \multirow{2}{*}{$\begin{array}{l}\text { Stopped } \\
\text { during } \\
\text { pregnancy }\end{array}$} & \multicolumn{3}{|c|}{$\begin{array}{c}\text { Smokers throughout pregnancy } \\
\text { (cigarettes/day) }\end{array}$} & \\
\hline & & & & $<5$ & $5-14$ & $>15$ & \\
\hline $\begin{array}{l}\text { I } \\
\text { II } \\
\text { III Non manual } \\
\text { III Manual } \\
\text { IV } \\
\text { V }\end{array}$ & $\begin{array}{l}3403 \\
3416 \\
3360 \\
3362 \\
3311 \\
3313\end{array}$ & $\begin{array}{l}3363 \\
3424 \\
3436 \\
3392 \\
3366 \\
3376\end{array}$ & $\begin{array}{l}3518 \\
3382 \\
3523 \\
3432 \\
3303 \\
3322\end{array}$ & $\begin{array}{l}3395 \\
3323 \\
3321 \\
3321 \\
3295 \\
3251\end{array}$ & $\begin{array}{l}3282 \\
3252 \\
3237 \\
3187 \\
3153 \\
3128\end{array}$ & $\begin{array}{l}3212 \\
3194 \\
3181 \\
3161 \\
3127 \\
3069\end{array}$ & $\begin{array}{l}3380 \\
3366 \\
3341 \\
3299 \\
3249 \\
3219\end{array}$ \\
\hline $\begin{array}{l}\text { Married, not classified } \\
\text { Unmarried }\end{array}$ & $\begin{array}{l}3366 \\
3245\end{array}$ & $\begin{array}{l}3467 \\
3099\end{array}$ & $\begin{array}{l}3393 \\
3267\end{array}$ & $\begin{array}{l}3294 \\
3208\end{array}$ & $\begin{array}{l}3026 \\
3034\end{array}$ & $\begin{array}{l}3148 \\
3092\end{array}$ & $\begin{array}{l}3270 \\
3143\end{array}$ \\
\hline Total & 3357 & 3385 & 3403 & 3307 & 3169 & 3144 & $3291 \mp 560$ \\
\hline
\end{tabular}

$n=16688$.

$\mathrm{I}=\mathrm{S}$.D.

smoking. More upper than lower class women stopped smoking before and during pregnancy, particulary before pregnancy. Women who were unmarried had smoking habits that were more extreme than those in social class $V(35.4 \%$ nonsmokers at the onset of pregnancy; $48 \cdot 5 \%$ smoking over four cigarettes a day at term). Those who were married but not classified on social class, for instance because their husbands were in the armed forces, had smoking patterns similar to women of social class III whose husbands were manual workers.

BIRTH WEIGHT BY SMOKING AND SOCIAL CLASS (table 2)

There was a difference of $215 \mathrm{~g}$ between mean birth
Table 3 Mean birth weight ${ }^{*}(g)$ by month after conception during which mother stopped smoking, singletons born 5-11 April 1970 in Britain

\begin{tabular}{cll}
\hline $\begin{array}{c}\text { Month of gestation during } \\
\text { which mother stopped smoking }\end{array}$ & $\begin{array}{l}\text { Mean } \\
\text { birthweight }\end{array}$ & $\begin{array}{l}\text { No of } \\
\text { mothers }\end{array}$ \\
\hline 1 & 3455 & 117 \\
$2-6$ & 3400 & 527 \\
7,8 & 3393 & 149 \\
9 & 3267 & 50
\end{tabular}

"Birth weight adjusted for maternal age, height, gravidity, duration of gestation, reported amount regularly smoked before stopping, and social class.

weights of infants of non-smokers and those who smoked 15 or more cigarettes a day at term, and this difference varied little across social class. Within every social class group there were similar 
decrements of birth weight with smoking. There was also an appreciable difference in birth weight across class (161 g difference between classes I and V). Much of this difference was a function of different patterns of smoking: among non-smokers, the difference between classes $I$ and $V$ was $90 \mathrm{~g}$ and for those who stopped smoking before pregnancy, there was no social class gradient.

BIRTH WEIGHT BY STAGE OF GESTATION AT WHICH SMOKING DURING PREGNANCY WAS STOPPED (table 3 )

Infants of women who stopped smoking during pregnancy, up to and including the eighth month of gestation, had birth weights similar to those of nonsmokers and significantly different from those of women who smoked throughout pregnancy. (These results were adjusted for maternal age, height, gravidity, gestation, social class, and the amount reported smoked before stopping.) Only those who stopped smoking during the ninth month of gestation had infants with birth weights not significantly different from that of infants of smokers throughout pregnancy (3267 g v $3202 \mathrm{~g}$ ).

BIRTH WEIGHT OF INFANTS WHOSE MOTHERS STOPPED SMOKING BEFORE CONCEPTION (table 4) Among women -who stopped smoking before pregnancy there was no relationship of the amount reported to have been smoked to birth weight nor little difference by social class. Thus smoking before conception appears to have no residual effect on birth weight.

MULTIPLE REGRESSION ANALYSIS ON BIRTH WEIGHT (table 5)

In this hierarchial linear multiple regression analysis social class III was divided into those whose husbands had either non-manual or manual occupations, and we used a six point scale to represent social class. After controlling for maternal age, height, and gravidity, being single was associated with a $136 \mathrm{~g}$ depression in birth weight $(\mathrm{p}<0.001)$ and there was a $23 \mathrm{~g}$ decrement in birth weight associated with one lower social class category $(\mathrm{p}<0 \cdot 001$, table $5 a)$. In other words, the difference between classes I and $\mathrm{V}$ would be $114 \mathrm{~g}$.

After controlling for the amount smoked, the birth weight decrement associated with being single dropped to $106 \mathrm{~g}$, a decline of $21 \%$, and that with each increment in social class to $14 \mathrm{~g}$, a decline of $37 \%$. Thus $37 \%$ of the association of birth weight with social class can be attributed to the differences in smoking habit across class.

PERINATAL MORTALITY BY SMOKING AND SOCIAL CLASS (table 6).

There is a strong relation of perinatal mortality with social class, and a less strong but still appreciable relation with smoking. Perinatal mortality rose from $7 \cdot 5 / 1000$ in social class I to $26 \cdot 8 / 1000$ in social class $\mathrm{V}$, and $37 \cdot 0 / 1000$ among infants of unmarried women.

Infants of women who smoked under five cigarettes a day had a perinatal mortality rate $(15 \cdot 9 / 1000)$ slightly lower than that for non-smokers $(18 \cdot 7 / 1000)$ and nearly equal to that for women who had stopped smoking during pregnancy (15.0/1000). For those who smoked between five and 14 cigarettes a day the rate was $26 \cdot 1 / 1000$ and for those who smoked 15 cigarettes and over, 28.3/1000. The perinatal mortality for infants of those who smoked five or more cigarettes'a day was $44.9 \%$ higher than the rate for non-smokers $\left(\chi^{2}=11 \cdot 05, p<0 \cdot 01\right)$.

There was interaction between smoking and social class in their relation to perinatal mortality (table 6B). Among the non-manual classes (I, II, and III non-manual), the rate for smokers of five or more

Table 4 Mean birth weight $(\mathrm{g})$ among infants of women who stopped smoking before conception, by amount smoked and social class, singletons, born 5-11 April in Britain

\begin{tabular}{|c|c|c|c|c|c|}
\hline \multirow[b]{2}{*}{ Social class } & \multicolumn{5}{|c|}{ Cigarettes/day } \\
\hline & $1-4$ & $5-14$ & $>15$ & All singletons & No of mothers \\
\hline $\begin{array}{l}\text { I } \\
\text { II } \\
\text { III Non manual } \\
\text { III Manual } \\
\text { IV } \\
\text { V } \\
\text { Married, not classified }\end{array}$ & $\begin{array}{l}3405(69) \\
3369(134) \\
3420(141) \\
3354(403) \\
3340(111) \\
3302(35) \\
3467(27)\end{array}$ & $\begin{array}{ll}3190 & (38) \\
3482 & (76) \\
3455 & (69) \\
3439 & (231) \\
3412 & (70) \\
3512 & (31) \\
3554 & (17)\end{array}$ & $\begin{array}{lr}3500 & (14) \\
3430 & (26) \\
3522 & (25) \\
3391 & (85) \\
3484 & (28) \\
3215 & (12) \\
3280 & (6)\end{array}$ & $\begin{array}{l}3348 \\
3412 \\
3441 \\
3386 \\
3383 \\
3372 \\
3474\end{array}$ & $\begin{array}{r}(121) \\
(236) \\
(235) \\
(719) \\
(209) \\
(78) \\
(50)\end{array}$ \\
\hline Unmarried & 3176 & 3007 & 3289 (9) & 3122 & (79) \\
\hline $\begin{array}{l}\text { All cases: } \\
\text { Mean birth weight }(g)\end{array}$ & $\begin{array}{l}3362 \\
(959)\end{array}$ & $\begin{array}{l}3410 \\
(563)\end{array}$ & $\begin{array}{l}3415 \\
(205)\end{array}$ & $3384 \pm 554$ & (1727) \\
\hline
\end{tabular}

$\mathrm{I}=\mathrm{S} . \mathrm{D}$.

( ) $=\mathbf{n}$. 
Table 5 Hierarchial multiple regression analysis with birth weight $(g)$ as dependent variable

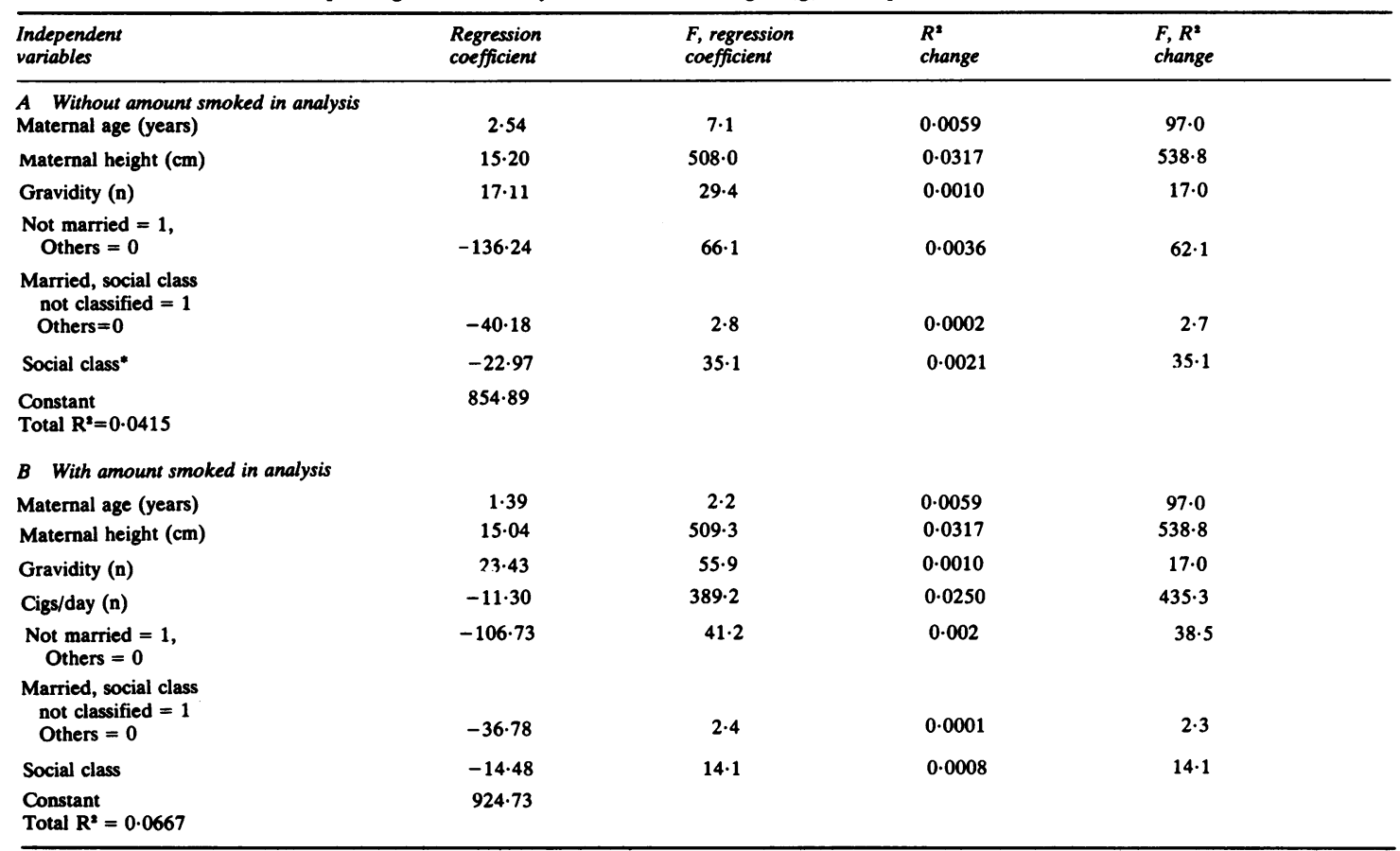

"Social class coded as follows: I $=1$, II $=2$, III non manual $=3$, III manual $=4$, IV $=5, \mathrm{~V}=6$.

$\mathrm{n}=16343$.

Table 6 Perinatal mortality rate per thousand, by amount smoked at term and social class, singletons, born 5-11 April 1970 in Britain

\begin{tabular}{|c|c|c|c|c|c|c|c|}
\hline \multirow{2}{*}{$\begin{array}{l}\text { A All smoking and social categories } \\
\text { Social class }\end{array}$} & \multicolumn{7}{|c|}{ Smoking status } \\
\hline & $\begin{array}{l}\text { Non- } \\
\text { smokers }\end{array}$ & $\begin{array}{l}\text { Stopped } \\
\text { during } \\
\text { pregnancy }\end{array}$ & $<5$ & $\begin{array}{l}\text { Cigarettes } \\
5-14\end{array}$ & $>15$ & \multicolumn{2}{|r|}{$\begin{array}{l}\text { All } \\
\text { cases }\end{array}$} \\
\hline $\begin{array}{l}\text { I } \\
\text { II } \\
\text { III Non-manual } \\
\text { III Manual } \\
\text { IV } \\
\text { V } \\
\text { Married, not classified } \\
\text { Unmarried }\end{array}$ & $\begin{array}{l}10 \cdot 5 \\
17 \cdot 8 \\
22 \cdot 2 \\
16 \cdot 0 \\
19 \cdot 9 \\
30 \cdot 0 \\
14 \cdot 1 \\
34 \cdot 8\end{array}$ & $\begin{array}{r}0 \cdot 0 \\
18 \cdot 9 \\
0 \cdot 0 \\
15 \cdot 3 \\
26 \cdot 8 \\
26 \cdot 3 \\
0 \cdot 0 \\
21 \cdot 1\end{array}$ & $\begin{array}{r}0 \cdot 0 \\
8 \cdot 2 \\
17 \cdot 2 \\
16 \cdot 5 \\
14 \cdot 4 \\
13 \cdot 7 \\
0 \cdot 0 \\
39 \cdot 6\end{array}$ & $\begin{array}{r}0 \cdot 0 \\
15 \cdot 4 \\
19 \cdot 9 \\
25 \cdot 0 \\
31 \cdot 8 \\
17 \cdot 8 \\
51 \cdot 7 \\
40 \cdot 4\end{array}$ & $\begin{array}{r}0.0 \\
6 \cdot 4 \\
33 \cdot 9 \\
21 \cdot 5 \\
42 \cdot 7 \\
38 \cdot 5 \\
26 \cdot 3 \\
41 \cdot 2\end{array}$ & & $\begin{array}{r}7 \cdot 5 \\
15 \cdot 9 \\
21 \cdot 2 \\
18 \cdot 8 \\
26 \cdot 2 \\
26 \cdot 8 \\
22 \cdot 3 \\
37 \cdot 0\end{array}$ \\
\hline All cases & $18 \cdot 7$ & $15 \cdot 0$ & $15 \cdot 9$ & $26 \cdot 1$ & $28 \cdot 3$ & & $21 \cdot 2$ \\
\hline \multicolumn{8}{|c|}{$\begin{array}{l}\text { B Smokers of five or more cigarettes/day contrasted with all others; non-manual social classes (I-III non-manual) contrasted with manual social classes (III } \\
\text { manual-V) }\end{array}$} \\
\hline Social class & & \multicolumn{2}{|c|}{ Non-smokers* } & $\begin{array}{l}\text { Smoked } \geqslant 5 \\
\text { cigarettes/day }\end{array}$ & \multicolumn{3}{|c|}{$\begin{array}{l}\text { All } \\
\text { cases }\end{array}$} \\
\hline $\begin{array}{l}\text { Non-manual I-III NM } \\
\text { Manual III M-V } \\
\text { Married, social class not classified } \\
\text { Unmarried }\end{array}$ & & \multicolumn{2}{|l|}{$\begin{array}{l}16 \cdot 6 \\
17 \cdot 8 \\
11 \cdot 5 \\
33 \cdot 5\end{array}$} & $\begin{array}{l}16 \cdot 7 \\
26 \cdot 8 \\
41 \cdot 7 \\
40 \cdot 8\end{array}$ & \multicolumn{3}{|c|}{$\begin{array}{l}16 \cdot 6 \\
21 \cdot 2 \\
22 \cdot 3 \\
37 \cdot 0\end{array}$} \\
\hline All cases & & \multicolumn{2}{|l|}{$18 \cdot 1$} & 26.9 & \multicolumn{3}{|c|}{$21 \cdot 2$} \\
\hline
\end{tabular}

"Includes those smoking < 5 cigarettes/day and those who stopped either before or during pregnancy.

$\mathrm{n}=16688$. 
cigarettes a day was $16 \cdot 7 / 1000$, whereas the rate for those smoking fewer than five cigarettes a day or not smoking was $16 \cdot 6 / 1000$. For the manual classes the rate for smokers of five or more cigarettes a day was $26 \cdot 8 / 1000,50 \cdot 6 \%$ higher than the rate of $17 \cdot 8 / 1000$ among lighter or non-smokers. Numbers were small, and caution is necessary, but it is striking that excess perinatal mortality, associated with smoking and lower social class (at least among offspring of married women), occurred only among those were both smokers and in the manual, or unclassifiable, social strata (table 6 B). Rates for unmarried women were high for both non-smokers and smokers.

MULTIPLE REGRESSION ANALYSIS ON PERINATAL MORTALITY (table 7)

Multiple regression analysis was used to adjust for possible confounding factors (age, height, gravidity) in the relation between cigarette smoking, social class, and perinatal mortality, and as a method to test the statistical significance of these relations. Given the results of tabular analysis (table 6), social class was coded as non-manual (I, II, III non-manual) or manual (III manual, IV, V), and those smoking five or more cigarettes a day throughout pregnancy were contrasted with all others. After controlling for age, height, and gravidity the rate for the non-manual group was $3 \cdot 6 / 1000$ lower than that of the manual group (ns), 21.6/1000 lower than for those not married $(F=16 \cdot 6, p<0 \cdot 001)$, and $6 \cdot 8 / 1000$ less than for married women who could not be classified (ns). When smoking was entered in the regression analysis before the social class variables, the relation with smoking was significant at entry into the analysis $\left(R^{2}=0.0007, F=11 \cdot 7, p<0.0001\right)$.

The interaction between smoking and manual $v$ non-manual social class (table 7c) did not quite reach the $5 \%$ level of significance $(F=3 \cdot 7)$. The result was not appreciably changed by controlling for age, gravidity, or height: excess perinatal mortality among the offspring of married women who could be classified for social class was restricted to those who both smoked and whose husbands were in the manual classes. When smoking was entered after the social class variables, the amount of variance accounted for by smoking fell to $R^{2}=0 \cdot 0005$, which was still highly significant $(F=8 \cdot 9, p<0 \cdot 001)$. The difference between manual and non-manual groups dropped from 3.6 to 2.7 per 1000 after controlling for smoking; while these differences were not significant, a quarter of the social class difference was accounted for by differences in smoking habit.

\section{Discussion}

There was a strong association between smoking and social class. At term, $48 \cdot 5 \%$ of unmarried women,
$46.0 \%$ of women in social class V but only $15.4 \%$ of women in social class I were smoking five or more cigarettes a day (table 1 ). Thus analyses separately relating social class or smoking to perinatal outcome could be severely confounded by the other, interrelated. independent variable.

While social class and smoking were strongly related, the relation of smoking to birth weight in this population did not differ widely across social class, against our expectations. Thus, given similar amounts smoked, there were similar decrements in birth weight. We had noted less effect of smoking on birth weight among upper social class women in the 1958 cohort, ${ }^{11}$ but no data were then available on the amount smoked, and since upper social class smokers in that survey might be presumed to have smoked fewer cigarettes than lower social class smokers, the difference in amount smoked may account for this seeming discrepancy. Thus whatever the mechanism for the depression of birth weight by maternal smoking, it appears to be little modified by social status at equivalent levels of smoking, parallel to the experience in our analysis of the Jerusalem perinatal study (D Rush et al , unpublished data).

In contrast, the effects of smoking and social class on perinatal mortality were highly interrelated. While numbers were small the pattern of results was remarkably similar: there was no excess of perinatal deaths among upper social class smokers or among married lower social class non-smokers but a $45 \%$ excess among lower social class smokers. Thus neither social class, nor smoking, alone conferred additional risk: both adverse factors appeared to be jointly necessary.

This is also similar to the results of many other studies, including the Ontario perinatal study, studied intensively by Meyer $^{12}$ and recently reanalysed. ${ }^{4}$

We are challenged, therefore, to consider why the excess perinatal mortality associated with cigarette smoking appears to be consistently so much greater among those of lower social class. We have hypothesised that it is related to sustained weight gain and nutrition among smokers with greater economic or educational resources. We have tested this hypothesis in our reanalysis of the Ontario data ${ }^{4}$ and more recently in the Jerusalem study (D Rush et $a l$, unpublished data), and find, so far, that upper social class smokers, with little or no excess perinatal mortality among their offspring, do sustain their weight gain in pregnancy. Indeed, in Jerusalem, the entire group of smokers had neither depressed weight gain nor increased perinatal mortality.

In our randomised trial of nutritional supplementation in pregnancy we did note that reversal of smoking induced birthweight depression 
Table 7 Hierarchial multiple regression analysis with perinatal mortality per 1000 as dependent variable*

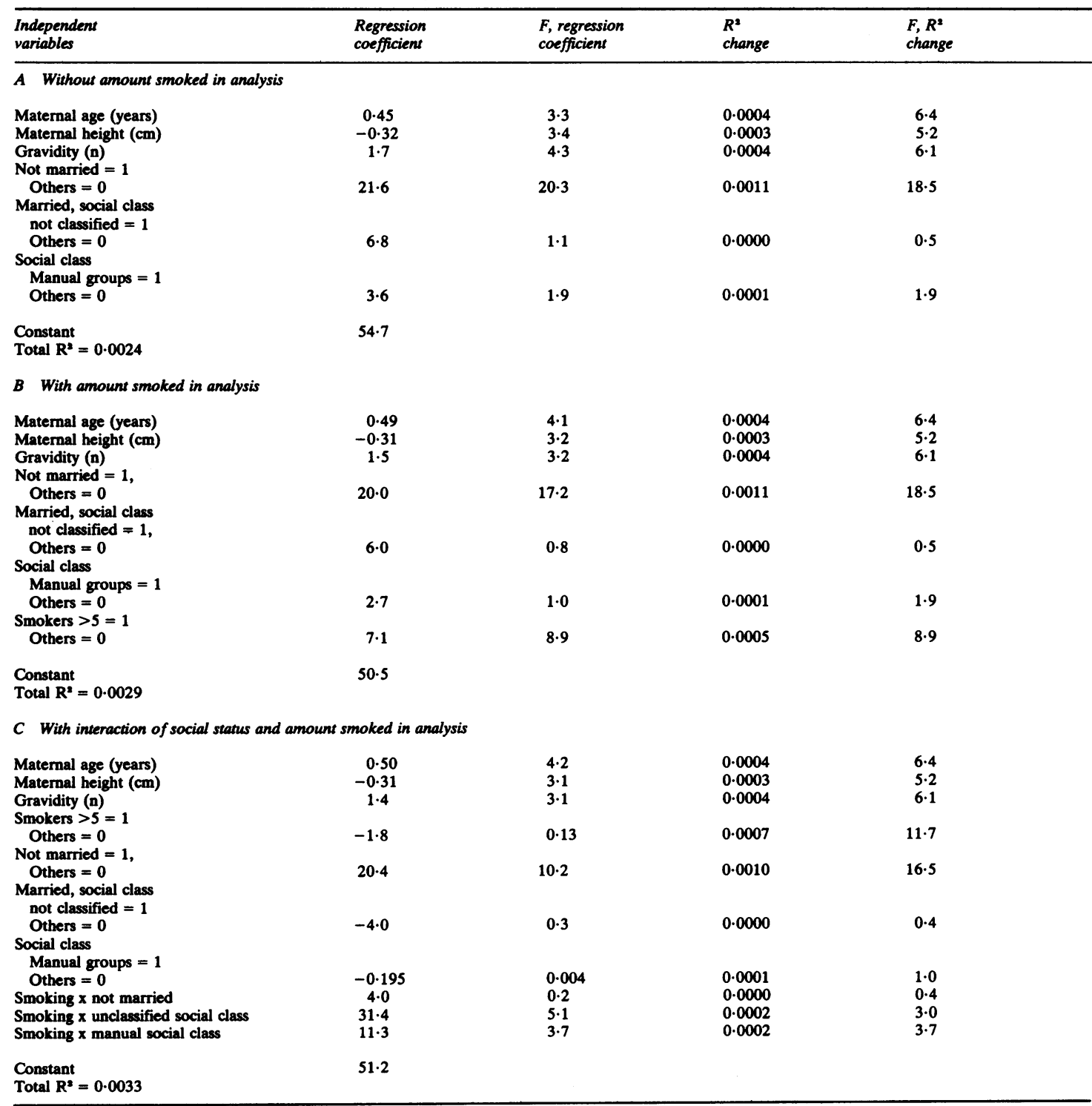

Coded as perinatal death $=1$, survivor $=0$.

$\mathrm{n}=16343$.

among heavy smokers who were given food supplements..$^{5}$ In the population under study here, however, birth weights of infants of upper social class smokers appear to be almost as depressed, after controlling for amount smoked, as lower social class smokers, although their risk of mortality is not increased.

It is not at all obvious how other hypothesised mechanisms for the effect of maternal cigarette smoking on the fetus, ${ }^{13}$ placenta praevia, abruptio placenta, ${ }^{14}$ or placental structural changes (D Rush et al, unpublished data) might be moderated by social status. On the other hand, several additional lines of research suggest the plausibility of nutritional mediation. Pirani and MacGillivray found pronounced depression among smokers of the normal physiological expansion during pregnancy of both total body water and plasma volume. ${ }^{15}$ Rosso 
and Streeter found that the starved pregnant rat does not normally expand plasma volume. ${ }^{16}$ Thus sustained diet by smokers may allow adequate placental perfusion, and sustained weight gain would indicate both adequate energy intake and storage, as well as normal maternal fluid expansion. The generally low incidence of mild toxemia in both smokers and women on restricted diets is consistent with plasma volume expansion mediating these observed relationships (M Campbell Brown and F D Johnstone, submitted for publication).

We acknowledge Dr Roma Chamberlain and Professor Geoffrey Chamberlain who were primarily responsible for the survey, Professor Neville Butler, Professor Jacob Cohen, and Dr Josephine Aresteh, our project officer at the National Institute of Child Health and Human development. Finally, we are indepted to the National Birthday Trust Fund, sponsor of this survey, for making these data available to us, and to the midwives who collected them.

Reprint requests to David Rush, MD, Rose F Kennedy Center, 1410 Pelham Parkway South, Bronx, New York 10461.

Supported by USPHS grants NICHD 5-RO1 HD13347 and 5-RO1 HD13370.

\section{References}

${ }^{1}$ Simpson WJ. A preliminary report on cigarette smoking and the incidence of prematurity. Am J Obstet Gynecol 1957; 73: 808-15.

${ }^{2}$ Rush D, Kass EH. Maternal smoking: a reassessment of the association with perinatal mortality. Am J Epidemiol 1972; 96: 183-96.
${ }^{3}$ Rush D. Examination of the relationship between birthweight, cigarette smoking during pregnancy and maternal weight gain. Journal of Obstetrics and Gynaecology of the British Commonwealth 1974; 81: 746-52.

${ }^{4}$ Rush D. Smoking, weight gain, and nutrition during pregnancy. Am J Obstet Gynecol 1981; 139: 233-4.

${ }^{5}$ Rush D, Stein Z, Susser M. Diet in pregnancy: a randomised controlled trial of nutritional supplements. March of Dimes Birth Defects Foundation. Vol XVI, No 3. New York: Alan R Liss, Inc, 1980.

${ }^{6}$ Rush D, Stein Z, Susser M. A randomised controlled trial of prenatal nutritional supplementation in New York City. Pediatrics 1980; 65: 683-97.

${ }^{7}$ Chamberlain R, Chamberlain G, Howlett BC, Claireaux A. The first week of life In: British births 1970. Vol 1. London: Heinemann, 1975.

${ }^{8}$ Chamberlain G, Philipp E, Howlett BC, Masters $\mathbf{K}$. Obstetric care. In: British births 1970. Vol 2. London: Heinmann, 1978.

' Butler NR, Alberman E. Perinatal problems. Second report of the 1958 British perinatal mortality survey. Edinburgh and London: E \& S Livingston, 1969.

${ }^{10}$ Butler NR, Goldstein H. Smoking in pregnancy and subsequent child development. Br Med J 1973; iv: 5735.

${ }^{11}$ Rush D. Cigarette smoking, nutrition, social status, and perinatal loss: their interactive relationships. In: Porter IH, Hook EB,eds. Human embryonic and fetal death. New York: Academic Press, 1980: 207-19.

${ }^{12}$ Meyer MB. How does maternal smoking affect birth weight and maternal weight gain? Am J Obstet Gynecol 1978; 131: 888-93.

${ }^{13}$ Longo LD. The biological effects of carbon monoxide on the pregnant woman, fetus and newborn infant. Am J Obstet Gynecol 1977; 129: 69-103.

${ }^{14}$ Meyer MB, Tonascia JA. Maternal smoking, pregnancy complications, and perinatal mortality. Am J Obstet Gynecol 1977; 128: 494-502.

${ }^{15}$ Pirani BBK, MacCillivray I. Smoking during pregnancy. Its effect on maternal metabolism and fetoplacental function. Obstet Gynecol 1978; 52: 257-63.

${ }^{16}$ Rosso P, Streeter MR. Effects of food or protein restriction on plasma volume expansion in pregnant rats.
$J$ Nutrition $1979 ; 109: 1887-1892$. 